\title{
Adaptações fonológicas na pronúncia de nomes de estabelecimentos comerciais brasileiros com elementos do inglês
}

\author{
Natália Cristine Prado \\ Universidade Federal de Rondônia (UNIR), Porto Velho, Rondônia, Brasil \\ natalia_cristine_prado@yahoo.com.br
}

DOI: $\underline{\text { http://dx.doi.org/10.21165/el.v45i1.681 }}$

\begin{abstract}
Resumo
Esta pesquisa tem como objetivo analisar as adaptações fonológicas que ocorrem nos nomes comerciais formados por elementos do inglês em contexto de Português Brasileiro, especificamente o processo de epêntese. Para realizar este estudo, primeiramente, coletamos nomes comerciais com elementos do inglês no interior do estado de São Paulo (Brasil) e, em seguida, submetemos uma amostra desses nomes comerciais que mantêm sua grafia inglesa à leitura por falantes do Português Brasileiro, com a intenção de comparar as realizações desses sujeitos com a pronúncia dessas palavras em Inglês Norte-Americano. Com este estudo, notamos que as adaptações na pronúncia dos anglicismos observados ocorreram para adequar as sîlabas inglesas ao padrão silábico do português.
\end{abstract}

Palavras-chave: nomes comerciais; Português Brasileiro; Inglês Norte-Americano; epêntese.

\section{Phonological Adjustments in the Pronunciation of Brazilian Trade Names with English Elements}

\begin{abstract}
This research aims to observe phonological adjustments in the pronunciation of trade names formed with elements of English in the context of Brazilian Portuguese, specifically the process of epenthesis. For this study, trade names with elements of English were first collected in São Paulo countryside (Brazil). Next, Brazilian speakers were required to read a sample of trade names that keep their English spelling to compare these speakers' pronunciation with the pronunciation of these words in North American English. It was noticed that adjustments in the pronunciation of Anglicisms were motivated to adapt English syllables to the Portuguese syllable pattern.
\end{abstract}

Keywords: trade names; Brazilian Portuguese; North American English; epenthesis.

\section{Introdução}

O principal objetivo deste estudo é analisar a formação de nomes comerciais com elementos do inglês em Português Brasileiro (doravante PB) observando principalme nte como os empréstimos se comportam fonologicamente nessa variedade da Língua Portuguesa. Pretendemos, com nossas análises, avaliar como falantes do PB pronunciam nomes comerciais criados a partir de palavras do inglês - enfocando o estudo das adaptações nos níveis fonético e fonológico, especificamente o processo de epêntese.

Sabemos, atualmente, que o empréstimo de palavras entre idiomas é um fenômeno natural e antigo. Para Paiva (1991, p. 109), "assim como importamos mercadorias de 
outros países, palavras estrangeiras também terão ampla acolhida no mercado linguís tico brasileiro". Entretanto, esse tema vem ganhando destaque no meio acadêmico, na mídia e até mesmo na política ${ }^{1}$ em razão da crescida quantidade de palavras emprestadas do inglês: os chamados anglicismos. Segundo a autora (PAIVA, 1991, p. 22), aprender inglês começou a se tornar muito importante e são diversos os motivos que levam as pessoas a estudar esse idioma. O inglês, para ela, é visto inclusive como uma forma de ascender socialmente e melhorar de vida.

De acordo com Carvalho (2009, p. 27-28), muitos anglicismos, como bife, rosbife e lanche, vieram diretamente da Inglaterra. No entanto, atualmente, com o deslocamento do centro do poder político para os EUA, os anglicismos passaram a ter origem, sobretudo, no Inglês Norte Americano (IA). Exemplos de vocábulos emprestados recentemente, já num momento de maior influência do IA, são palavras como pen drive, skate e design (CARVALHO, 2009, p. 28).

No contexto comercial, é muito importante que o produto a ser vendido alcance cada vez mais consumidores, ou seja, "fale" com o maior número de pessoas. Nesse sentido, a questão fundamental a ser pensada pelos grandes comerciantes e publicitários diante de um mundo "globalizado" é como negociar de modo eficiente em nível global e, para isso, muitos investem não só em publicidade em outros idiomas, mas nomeiam seu produto com palavras de uma língua que eles acreditam que muitas pessoas conheçam (ou que tenha prestígio), isto é, um idioma que tenha um papel de língua global. Atualmente, enquanto o inglês é reconhecido por muitas pessoas como uma língua de alcance global (CRYSTAL, 2003) - e muitos comerciantes escolhem palavras desse idioma para nomear seus produtos e negócios - muitas indústrias, lojas e marcas importadas, às vezes dos EUA, também entram na competição pelo mercado consumidor de diversos países. Produtos importados, em alguns casos, podem não ser acessíveis a todos os consumidores por conta do seu valor monetário mais alto que os produtos nacionais, o que faz com que, tradicionalmente, eles fiquem restritos à parcela da população economicamente privilegiada, adquirindo, assim, um status sofisticado. Por isso, podemos dizer que, no uso de elementos da língua inglesa na formação de nomes comerciais, há muito mais uma necessidade simbólica de identificação social e cultural do que propriamente a de nomear um novo objeto ou produto.

Levando em consideração o grande número de palavras da língua inglesa que circula de várias formas no $\mathrm{PB}$, sempre surgem pesquisas sobre os anglicismos. Esses estudos, como afirma Paiva (1991, p. 127), vêm seguindo duas posturas diferentes: parte dos autores defende, de modo intransigente, o idioma nacional de uma influência estrangeira, enquanto a outra parte, com postura mais liberal, considera esse fenômeno uma consequência normal do desenvolvimento de qualquer língua. Todavia, ainda são poucos os estudiosos que têm se dedicado mais especificamente aos estudos da adaptação de estrangeirismos à fonologia do português. Dentre os trabalhos que observam este fenômeno, podemos destacar os estudos de Freitas (1984, 1992), Freitas et al. (2003),

\footnotetext{
${ }^{1}$ Não podemos deixar de nos referir aqui ao Projeto de lei n. ${ }^{\circ} 1676$ de 1999 do então deputado Aldo Rebelo. Este Projeto dispunha sobre "a proteção, a defesa e o uso da Língua Portuguesa" e visava à proibição do uso de palavras estrangeiras, sobretudo os anglicismos, no PB. Na época, o assunto gerou grande revolta na comunidade linguística, que se manifestou contrária ao Projeto (FARACO, 2004; FIORIN, 2004; GARCEZ; ZILLES, 2004; MASSINI-CAGLIA RI, 2004a, 2004b; ZILLES, 2004; CARVALHO, 2009). Posteriormente, es se Projeto foi reformulado e aprovado pelo Senado em uma nova versão que foi proposta pelo senador Amir Lando, em 28 de maio de 2003.
} 
Assis (2007), Massini-Cagliari (2010, 2011a, 2011b, 2013), Souza (2011), Prado (2014) e Macedo (2015). Assim como os trabalhos citados, este estudo tem o intuito de contribuir para as análises das adaptações fonológicas que podem acontecer quando um termo de uma língua estrangeira é inserido no contexto linguístico do português. Deste modo, pretendemos estudar o status fonológico dos anglicismos presentes no meio comercial em PB, observando especificamente os casos de epêntese.

\section{Procedimentos metodológicos}

Para dar início aos nossos estudos, primeiramente, coletamos nomes comerciais com elementos do inglês na região interiorana do estado de São Paulo. Para nossa busca, usamos o site Guia Mais ${ }^{2}$, que contém a informação comercial dos 26 estados do Brasil e do Distrito Federal. A partir desse site, pudemos, com facilidade, observar os nomes comerciais do interior de São Paulo; além disso, as empresas estão separadas por categorias, o que facilitou a busca, a separação, a categorização e a quantificação dos dados. Com essa pesquisa, conseguimos consultar um total de 7271 estabelecimentos cadastrados no interior de São Paulo, sendo que 862 deles têm algum elemento da língua inglesa. Big Lar Móveis, City Pão, Clean Plus, Mister Jovem, All Car Peças e Libertway Motel são exemplos de nomes comerciais que se encontram em nosso corpus.

Posteriormente à coleta dos dados, realizamos a preparação de um experimento de leitura que tem como intenção observar a pronúncia dos nomes comerciais por falantes de PB. Como a produtividade do empréstimo de palavras do inglês em nomes comerciais é relativamente alta no nosso corpus, para esse experimento, foi escolhida apenas uma amostra de 184 nomes comerciais com palavras da língua inglesa que mantêm sua grafia original e que pertencem a diferentes setores do comércio e serviços. Os nomes comerciais foram apresentados em contexto de língua portuguesa em frases criadas para este experimento.

Após a escolha dos nomes e a montagem do experimento de leitura, selecionamos os informantes para a realização desta etapa. Consideramos, como melhor opção, a escolha de falantes adolescentes ou adultos, a partir do critério de familiaridade com a ocorrência de estrangeirismos nas duas modalidades da língua, oral e escrita. Dessa forma, selecionamos dez informantes residentes no interior de São Paulo (na cidade de Itirapina), sendo que cinco deles nunca tinham estudado inglês em escolas de idiomas e cinco já estudavam inglês há dois anos. Para facilitar a identificação da pronúncia de cada informante, utilizamos as abreviações PB-S-X para nos referirmos aos informantes do PB que não estudam inglês, PB-C-X para os informantes do PB que estudam inglês.

Realizamos as gravações diretamente no computador em uma interface com o PRAAT, utilizando o conjunto de fone e microfone Microsoft ${ }^{\circledR}$ LifeChat $^{\mathrm{TM}}$ LX-3000, o que garantiu a qualidade sonora para a realização das análises, e não se explicitou o objetivo do experimento para o informante para não se influenciar seu resultado. Após as gravações, selecionamos 40 nomes comerciais que apresentavam contextos para diferentes processos fonológicos e realizamos a transcrição dos dados de acordo com o alfabeto fonético IPA, fazendo, em seguida, as análises fonológicas.

\footnotetext{
2 www.guiamais.com.br.
} 


\section{Os casos de epêntese}

Nesta seção, analisaremos os casos de epêntese que ocorreram na pronúncia dos nomes comerciais com elementos do inglês no contexto de língua portuguesa. Cagliari (1999, p. 132) explica que a inserção ou epêntese de uma vogal acontece para tornar uma sílaba canônica, desfazendo uma estrutura mal formada, sendo que essa inserção pode aparecer no início, no meio ou no final de palavras. O IA e o português diferem com relação aos moldes silábicos; dessa maneira, geralmente ocorrem ajustes silábicos na passagem de uma língua para a outra. Quanto à estrutura de suas silabas, o inglês permite núcleo simples ou complexo, onset simples ou complexo, coda simples ou complexa, sendo que nem o onset nem a coda são obrigatórios.

De acordo com Hogg e McCully (1999[1987], p. 35), o inglês apresenta 12 padrões silábicos para monossílabos tônicos e 3 para monossílabos átonos, como se pode ver no quadro 1:

\begin{tabular}{|l|l|l|l|l|l|}
\hline \multicolumn{3}{|l|}{ Monossílabos Tônicos } & \multicolumn{2}{l|}{ Monossílabos Átonos } \\
\hline Id & VC & isle & VV & a & V \\
\hline Bad & CVC & bye & VVC & an & VC \\
\hline brad & CCVC & bide & CVV & the & CV \\
\hline band & CVCC & bind & CVVCC & \multicolumn{2}{|}{} \\
\cline { 1 - 3 } brand & CCVCC & brid & CCVVC & & \\
\cline { 1 - 3 } I & V & grind & CCVVCC & & \\
\cline { 1 - 2 }
\end{tabular}

Quadro 1. Molde silábico do inglês (adaptado de HOGG; McCULLY, 1999[1987], p. 35)

No entanto, o quadro 1 não dá conta de sílabas do tipo CCCVCCCC, como em strengths, por exemplo, e de algumas outras sillabas da língua. Diante desse problema, concordamos com Roach (1998, p. 71-74), que afirma que essa é a maior estrutura silábica do inglês: três consoantes em onset e até quatro consoantes em coda silábica. Collischonn (2005[1996], p. 117) explica que não há consenso entre os estudiosos em relação ao molde silábico do $\mathrm{PB}$, que determina o número máximo e mínimo de elementos permitidos em uma sîlaba desta língua. A autora define os seguintes padrões silábicos para o PB:

\begin{tabular}{|l|l|}
\hline $\mathrm{V}$ & é \\
\hline VC & ar \\
\hline VCC & nsstante \\
\hline CV & cá \\
\hline CVC & lar \\
\hline CVCC & $\underline{\text { monst }}$ tro \\
\hline CCV & tri \\
\hline CCVC & tres \\
\hline CCVCC & transporte \\
\hline VV & aula \\
\hline CVV & lei \\
\hline CCVV & grau \\
\hline CCVVC & claustro \\
\hline
\end{tabular}

Quadro 2. Padrões silábicos do PB (COLLISCHONN, 2005[1996], p. 117)

Ainda em relação ao português, Cagliari (2007, p. 116) propõe os moldes silábicos apresentados no quadro $3^{3}$ :

\footnotetext{
${ }^{3}$ No quadro 3, M significa monotongo, D significa ditongo e T significa tritongo.
} 


\begin{tabular}{|c|c|c|c|}
\hline $\begin{array}{l}\text { Padrão } \\
\text { Silábico }\end{array}$ & Exemplo & $\begin{array}{l}\text { Forma } \\
\text { ortográfica }\end{array}$ & \\
\hline \multirow[t]{2}{*}{$\mathrm{V}$} & {$[\varepsilon]$} & $\bar{E}$ & $\bar{M}$ \\
\hline & {$[\mathrm{e} \oplus]$} & $\mathrm{Eu}$ & $\mathrm{D}$ \\
\hline $\mathrm{CV}$ & [pe] & Pé & $\mathrm{M}$ \\
\hline \multirow[t]{2}{*}{$\mathrm{CV}$} & [teø] & Teu & $\mathrm{D}$ \\
\hline & {$[\mathrm{k} \oplus a \oplus]$} & Qual & $\bar{T}$ \\
\hline \multirow[t]{2}{*}{$\mathrm{CCV}$} & [kru] & Cru & $\bar{M}$ \\
\hline & [kreø] & Creu & $\mathrm{D}$ \\
\hline \multirow[t]{2}{*}{$\mathrm{VC}$} & {$[\varepsilon s]$} & És & $\mathrm{M}$ \\
\hline & [ets] & Eis & $\mathrm{D}$ \\
\hline \multirow[t]{2}{*}{$\mathrm{VCC}$} & $\left[\begin{array}{ll}\text { xil } & \text { I) }\end{array}\right)$ s $]$ & Ruins & M \\
\hline & {$[$ [léo)ı)/s] } & Leões & $\bar{D}$ \\
\hline \multirow[t]{3}{*}{ CVCC } & [pes] & Pés & $\bar{M}$ \\
\hline & [teøs] & Teus & $\bar{D}$ \\
\hline & [køats] & Quais & $\mathrm{T}$ \\
\hline \multirow[t]{3}{*}{ CVCC } & [perspekttiva] & Perspectiva & $\mathrm{M}$ \\
\hline & $[\mathrm{me}) \mathrm{t} / \mathrm{s}]$ & Mães & $\bar{D}$ \\
\hline & {$[$ ságøo)t)s] } & Saguões & $\mathrm{T}$ \\
\hline \multirow[t]{2}{*}{$\mathrm{CCVC}$} & [plastık@] & Plástico & $\bar{M}$ \\
\hline & [u)mbrats] & Umbrais & $\mathrm{D}$ \\
\hline \multirow[t]{2}{*}{ CCVCC } & $\left.[\mathrm{tre}))_{\mathrm{s}}\right]$ & Trens & $\bar{M}$ \\
\hline & $[\mathrm{k} \square \mathrm{b}(\mathrm{s}) \mathrm{l}) \mathrm{s} / \mathrm{s}]$ & Cobrões & $\mathrm{D}$ \\
\hline
\end{tabular}

Quadro 3. Sílabas do português (CAGLIARI, 2007, p. 116)

Collischonn comenta os trabalhos de Câmara Jr. (2010[1969]), Lopez (1979) e Bisol (1989), que refletem sobre a questão dos moldes silábicos. Embora Câmara Jr. (2010[1969]) não tenha feito um estudo dos moldes silábicos, podemos deduzi-lo a partir de sua análise. Para ele, a sílaba é formada de um aclive, de um ápice e de um declive, como no exemplo (1):

(1)

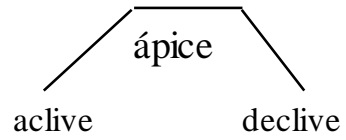

Nesta representação, o ápice é constituído por uma vogal, o aclive, por uma ou duas consoantes e, por fim, o declive, por uma das seguintes consoantes: /S/, /r/, /l/. Além dessas possibilidades, o declive pode apresentar uma consoante nasal - já que o autor interpreta as vogais nasais como sendo fonologicamente vogais fechadas por consoante nasal. Essa análise admitiria seis segmentos na silaba, como, por exemplo, na palavra grãos, que, fonologicamente, teria a representação /grawNS/, como no exemplo (2), em que a ideia de Câmara Jr. aparece representada a partir da estrutura arbórea adotada posteriormente pelos modelos não-lineares.

(2)

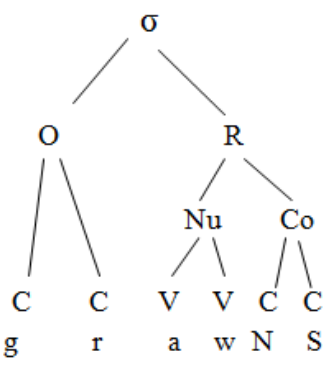


Segundo Collischonn (2005[1996], p. 118), esse molde é inadequado, pois não há, em português, sequências de ditongo e duas consoantes (como *cairs e *peuls); dessa forma, seria necessário que a esse molde fossem acrescentadas algumas restrições, a fim de evitar essas sequências. Já Lopez (1979) propõe dois moldes: um para sîlaba subjacente e outro para silaba de superfície. Na silaba subjacente, a autora considera até quatro elementos, sendo dois no onset e dois na rima. Segundo Collischonn, a proposta de Lopez pode ser traduzida na representação (3), na qual as chaves indicam diferentes alternativas de preencher um mesmo constituinte.

(3)

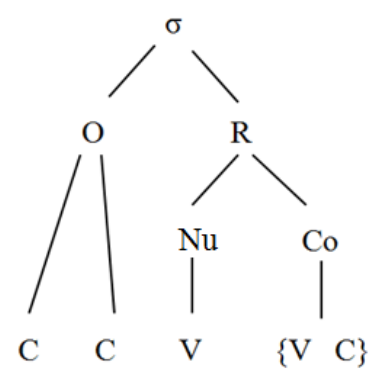

Esse molde, significativamente reduzido em relação ao de Câmara Jr., exclui as sîlabas inexistentes, mas também exclui as existentes, como deus, dois e caústico. No entanto, na forma fonética, esse molde muda, admitindo três elementos no onset (como em criança e prior). Diferentemente de Câmara Jr., Lopez acredita que ditongos nasais têm a forma subjacente $\mathrm{VnV}$, assim, grão tem a forma subjacente /granu/. Dessa forma, na ótica de Lopez, os ditongos nasais derivam de duas sîlabas, das quais a segunda é iniciada por consoante nasal, que é apagada, passando a VV na superfície. A essa silaba, podemos acrescentar o morfema de plural, o que faria com que a rima ficasse com três elementos e não quatro, como na proposta de Câmara Jr. Todavia, para Bisol (1989), o ditongo nasal deriva de uma sequência de VC subjacente, em que $\mathrm{C}$ se torna flutuante e uma vogal temática é acrescida. A associação posterior do traço nasal à rima cria o ditongo nasal. Para Collischonn (2005[1996], p. 120), esses dados indicam que a sequência de segmentos se ajusta ao padrão silábico CCVCC, cobrindo as sîlabas máximas, como fausto e monstro.

No entanto, de acordo com Câmara Jr. (2004[1970], p. 54), as semivoga is funcionam como consoante, ou seja, ocupam posições na silaba normalmente reservadas a consoantes, mas são de natureza vocálica, ou seja, foneticamente são articuladas e compreendidas como vogais. Desse modo, surge uma dúvida acerca da representação das sîlabas que contêm ditongos: seriam CVC ou CVV? O molde CVC pressupõe uma sîlaba travada, enquanto que CVV, uma sílaba aberta. Embora esta seja uma discussão importante para o levantamento dos tipos silábicos do português e para outras questões que envolvem a determinação do peso e da estrutura silábica (como o posicionamento do acento lexical), neste trabalho, admitiremos que o glide está posicionado no núcleo, seguindo a opinião de Câmara Jr. (2004[1970]), uma vez que a diferenciação de posicionamento do glide no núcleo ou na coda não afeta as análises desenvolvidas neste artigo $^{4}$. Assim, considerando-se o glide no núcleo da sílaba, uma palavra como "grãos" teria a estrutura CCVVCC, conforme propõe Câmara Jr.. Pode-se assumir que a sílaba

\footnotetext{
${ }^{4}$ Para conhecer os argumentos contrários ao posicionamento do glide no núcleo silábico em ditongos decrescentes do PB, remetemos o leitor ao trabalho de Bisol (1989) e Zucarelli (2002).
} 
máxima do PB é, então, CCVVCC e não CCVCC, como observado nos quadros anteriores.

Freitas e Neiva (2006, p. 6) explicam que, em relação ao onset do inglês, quando as três posições possíveis são preenchidas, $\mathrm{C} 1$ deve ser obrigatoriamente a fricativa alveolar surda [s]; em posição de C2 só podem ocorrer oclusivas surdas, ou seja [p, t, k]; e C3 é ocupado apenas por líquid as ou glides, ou seja, [1, I, j, w]. Ademais, as combinações possíveis destas consoantes também são restritas. Quando todas essas posições são preenchidas, a consoante mais próxima ao núcleo (C3) é uma soante contínua e pode vir precedida imediatamente por uma obstruinte não sonora $(\mathrm{C} 2)$. Já a posição $\mathrm{C} 1$ só pode ser ocupada, nesse caso, pelo segmento [s]. No entanto, quando as consoantes do onset são apenas duas, há um número maior de possibilidades e, se a consoante em $\mathrm{C} 1$ é uma fricativa alveolar surda, [s], ampliam-se ainda mais os tipos de combinações de segmentos. Nesse caso, a posição C2 pode ser ocupada por uma soante (exceto a palatal [j] e a velar [n]), por uma obstruinte surda não contínua, ou ainda por [f], esta última uma sequência rara na língua. Quando qualquer outra obstruinte diferente de [s] preenche $\mathrm{C} 1$, a posição C2 fica restrita a glides e líquidas.

Segundo Cagliari (2007, p. 117), nas silabas CV em PB, o onset pode ser qualquer consoante, porém não ocorre o tepe em início de palavras, e a lateral e a nasal palatais, no mesmo contexto, ocorrem só em poucas palavras do português. Já nas silabas CCV (contendo $\mathrm{C} 1$ e C2), C2 será ou um tepe ou uma lateral alveolodental e, quando C2 for tepe, $\mathrm{C} 1$ pode ser qualquer oclusiva ou fricativa labiodental. Já quando $\mathrm{C} 2$ for uma lateral alveolodental, C1 poderá ser qualquer oclusiva, exceto oclusiva dental sonora, ou ainda, poderá ser uma fricativa labiodental desvozeada, como podemos observar no quadro 4:

\begin{tabular}{|ccc|}
\hline $\mathrm{C} 1$ & $\mathrm{C} 2$ & $\mathrm{~V}$ \\
$\mathrm{p}, \mathrm{b}, \mathrm{t}, \mathrm{d}, \mathrm{k}, \mathrm{g}, \mathrm{f}, \mathrm{v}$ & $\mathrm{r}$ & $\mathrm{V}$ \\
$\mathrm{p}, \mathrm{b}, \mathrm{t} \quad \mathrm{k}, \mathrm{g}, \mathrm{f}$ & $\mathrm{l}$ & $\mathrm{V}$ \\
\hline
\end{tabular}

Quadro 4. Possibilidades do onset em português (CAGLIARI, 2007, p. 117)

Collischonn (2005[1996], p. 120) acredita que, em língua portuguesa, determinadas sequências de segmentos não são permitidas no onset complexo. Nessa posição, as sequências permitidas são plosiva + líquida; entretanto, os grupos /dV/, /tl/ e /vl/, apesar de permitidos pelo molde, são restritos a nomes próprios de origem estrangeira, como Vladimir. A autora também considera que o grupo /t1/ ocorre na palavra atlas e seus derivados. No entanto, podemos encontrar o grupo /d1/ em siglas, como em DLA (Departamento de Linguística Aplicada). Além disso, em posição inicial de palavra, não ocorre $/ \mathrm{n} /$ e $/ \lambda /$, de modo que só encontramos esses segmentos nessa posição em palavras emprestadas de outras línguas, como, por exemplo, lhama e nhoque.

Sobre o núcleo do IA, que pode ser simples ou ramificado, Wells (2008) apresenta os seguintes ditongos /ei/ (day), /ai/ (try), /oi/ (boy), /ov/ (show) e /av/ (now). Em relação ao núcleo do $\mathrm{PB}$, que também pode ser simples ou ramificado, os ditongos podem ser classificados em ditongos crescentes e decrescentes (CÂMARA Jr., 2004[1970], p. 56). Os ditongos decrescentes são aqueles em que a proeminência silábica ocorre na primeira vogal e os ditongos crescentes são aqueles em que a proeminência silábica ocorre na segunda vogal, sendo que os ditongos nasais são sempre decrescentes. Para o autor, há um único caso de ditongo crescente em PB que nunca se realiza como hiato: a vogal assilábica / $\mathrm{u} /$ depois de plosiva labial / $\mathrm{k}, \mathrm{g} /$ antes de vogal silábica, como na palavra qual, 
que produz o que o autor chama de "tritongo". Collischonn (2005[1996], p. 121) também acredita nessa ideia, dizendo que "há um tipo de ditongo crescente que não alterna com hiato. Trata-se de kw/gw, seguidos de a/o". Já Bisol (1989) defende a não ocorrência de ditongos crescentes e interpreta estes casos como fonemas velares labializados: $/ \mathrm{k}^{\mathrm{w}} / \mathrm{e}$ $/ \mathrm{g}^{\mathrm{W}} /$.

Freitas e Neiva (2006) comentam que, como a língua inglesa permite um agrupamento de até quatro consoantes em coda de final de palavra, considerando-se a sîlaba do ponto de vista fonético, essa particularidade da língua inglesa impõe grandes dificuldades para os falantes brasileiros, cuja língua materna permite a ocorrência de no máximo dois segmentos consonânticos ao final de silabas, com restrições muito limitadas quanto à classe de consoantes possíveis em tal posição.

Nas sîlabas VC, conforme Cagliari (2007), a coda do PB poderá ser uma fricativa alveodental ou palatoalveolar, dependendo do dialeto, uma nasal qualquer ou uma rótica. Já nas sîlabas VCC (contendo C3 e C4), C3 poderá ser uma nasal palatal ou velar ou uma rótica. Já C4 será sempre uma fricativa alveolar ou palatoalveolar, variando de acordo com o dialeto. Este último caso, lembra o linguista, ocorre somente em poucas palavras da língua, como nas palavras perspectiva e perspicaz. Cagliari (2007, p. 117) afirma que "no português brasileiro, algumas palavras variam foneticamente, podendo ter uma sílaba a mais ou a menos, dependendo de uma vogal breve e átona, em geral $[1]^{5}$, entre uma oclusiva, uma nasal bilabial ou uma fricativa alveolar surda, por um lado, e uma outra consoante por outro lado". Já, para Lee (1993), a vogal epentética do PB é sempre, fonologicamente, /e/, já que este é o único segmento não-especificado na representação de base, que pode assumir as formas fonéticas de [e] ou [i]. Quanto aos estrangeiris mos em específico, Lee (1993, p. 848) diz que "o falante nativo de português insere /e/ quando pronuncia palavras estrangeiras e siglas que têm os sons de [-soa] na posição final da sílaba".

Como vimos, o padrão silábico da língua inglesa admite até três consoantes na posição de onset, diferentemente do português, que, para esta posição, admite apenas duas, obedecendo à fonotática da língua, que impõe restrições de agrupamento. Assim, algumas combinações que são possíveis de realização no IA não o são no PB (como é o caso da fricativa desvozeda [s] seguida de uma ou mais consoantes $(\langle\mathrm{sp}\rangle,\langle\mathrm{st}\rangle,\langle\mathrm{str}\rangle$, $<$ spr >) em início de sílaba). Por esse motivo, o falante do PB tem a propensão de acrescentar a vogal anterior alta [i] cada vez que se depara com clusters consonantais inexistentes em seu sistema fonológico.

Neste trabalho, identificamos a epêntese em suas duas formas de realização (inicial e final). Em PB, os casos de prótese (em início de palavras) foram motivados pelo não licenciamento de onsets compostos pelas sequências <sp> (palavras sport ${ }^{6}$ e speed) e <str> (palavra street) e foram realizados na maioria das pronúncias dos informantes (apenas uma realização no PB-S e duas no PB-C na palavra street não apresentaram esse fenômeno).

Já os casos de paragoge (no sentido de epêntese em final de palavra, não rítmica) em PB aconteceram em virtude do não licenciamento de oclusivas (/t/ - sport, /d/ - speed, /p/ - stop, /g/ - bag, /k/ - tech), fricativas (/f/ - beef $f^{7}, / \mathrm{g} /$ - brush) e nasal alveodental (/n/ -

\footnotetext{
${ }^{5}$ A vogal representada por [1], em Cagliari (2007), corresponde a [I], no padrão atual do IPA.

${ }^{6}$ A palavra sport, enquanto nome comum, já está ortograficamente adaptada ao português esporte.

${ }^{7}$ A palavra beef, enquanto nome comum, já está ortograficamente adaptada ao português bife.
} 
design $)^{8}$ na posição de coda no PB. A vogal [i], acrescentada por epêntese, desencadeou um processo de ressilabação das palavras, uma vez que a vogal epentética passa a ser núcleo de uma nova sîlaba, como exemplificado em (4), (5), (6) e (7).

(4) Speed

IA

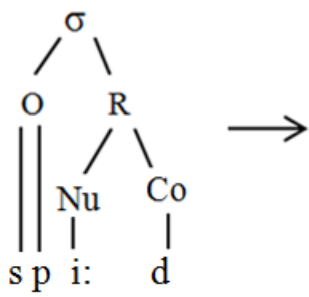

PB

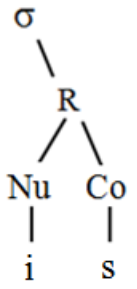

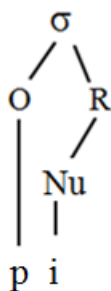

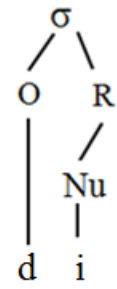

(5) Street

IA

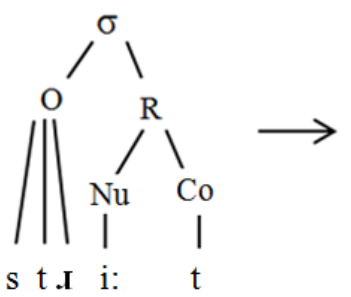

PB

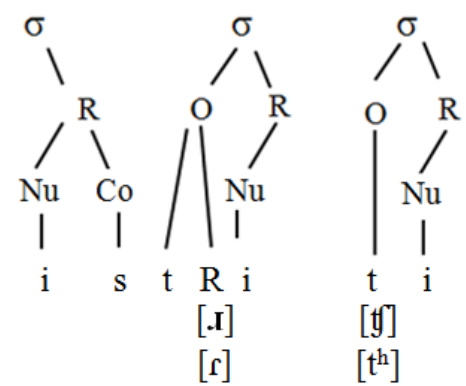

(6) Beef

IA<smiles>CCC1NC2OON1O2</smiles>

A<smiles>C1CP(N2CO2)OO1</smiles>

d i

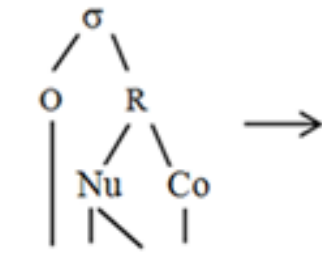

$\mathrm{z}$ a $\mathrm{I}$ n
PB

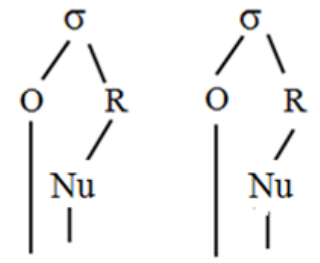

b $\quad$ i $\quad f \quad i$

(7) Design

PB

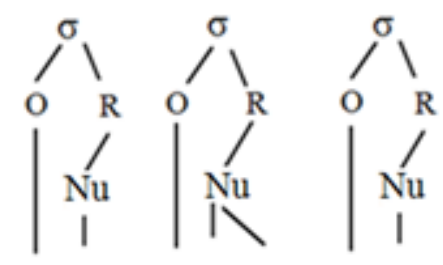

d $\quad$ i $\quad z$ a $\quad$ i $\quad n$ i

\footnotetext{
${ }^{8}$ Câmara Jr (2004[1970], p.52) considera como sendo apenas quatro as consoantes portuguesas possíveis
} em posição pós-vocálica, a saber/S/, /N/, /l/ e /R/. 
Assim, as palavras speed e street, que tinham apenas uma silaba em IA, passaram a ter três sîlabas em português; a palavra beef, que também tinha uma sîlaba em IA, passou a duas silabas em português; e, por fim, a palavra design, que tinha duas sîlabas em IA, passou a ter três em português. Com relação à palavra design, só há contexto para a epêntese porque $\mathrm{o} / \mathrm{n} /$ final não nasalizou as vogais anteriores na pronúncia de algun $\mathrm{s}$ sujeitos da pesquisa. Entretanto, em algumas realizações de informantes do PB-C, não ocorre epêntese no caso da palavra design, que passa a ser pronunciada com o /i/ final nasalizado [I)].

Notamos que os casos observados para o PB na pronúncia de nomes comerciais são semelhantes aos casos de epêntese mapeados na adaptação de nomes comuns, estudados por Assis (2007), e de nomes próprios, observados por Massini-Cagliari (2010, 2011a, 2011b, 2013) e Souza (2011). Em relação aos nomes comuns, Assis (2007, p. 154) constatou a ocorrência da epêntese para "resolver" sílabas não canônicas em $\mathrm{PB}$, como no caso da palavra spam, um monossílabo em IA que passa a ter duas sîlabas em PB após a epêntese (/spæm/ em IA e /iS.paN/ em PB). O mesmo foi constatado em relação aos nomes próprios, assim, o nome Robert pode ser adaptado para [h $\square$.ber.tfi], com três silabas e uma vogal epentética no fim da palavra (MASSINI-CAGLIARI, 2011a, p. 62), e o nome Steve que, ao ser adaptado ao $\mathrm{PB}$, também fica com três sîlabas após duas epênteses (/iS.ti.vi/) (SOUZA, 2011, p. 195).

\section{Considerações finais}

O estudo dos nomes comerciais pode ser de interesse para várias disciplinas, como a publicidade e os estudos linguísticos - além de despertar a curiosidade das pessoas de modo geral. Tanto do ponto de vista dos publicitários quanto do ponto de vista dos comerciantes é essencial ter um nome que chame a atenção do público consumidor. Assim, diante desse contexto, no meio comercial o inglês acaba sendo visto como uma forma interessante de valorização do produto que está sendo vendido, isto é, os comerciantes acham mais "chique" um salão de beleza chamado Angel's Hair do que, simplesmente, Cabelo de Anjo - talvez numa tentativa de associar aquele estabelecime nto a um público-alvo formado por pessoas de maior poder aquisitivo.

A pesquisa realizada neste estudo observa as adaptações fonológicas que ocorrem na pronúncia de nomes comerciais com elementos do inglês por falantes de $\mathrm{PB}$, focando especificamente nos casos de epêntese. Notamos com esse estudo que o PB tende a realizar epênteses para "resolver" sílabas que não são possíveis nessa língua. De modo geral, as análises das adaptações fonológicas de estrangeirismos presentes no léxico comercial corroboram os resultados alcançados por outros autores em pesquisas anteriores (FREITAS, 1984, 1992; FREITAS et al., 2003; FREITAS; NEIVA, 2006; ASSIS, 2007; SOUZA, 2011) de que as primeiras adaptações que acontecem com anglicismos, quando realizados por falantes de português, ocorrem no nível fonéticofonológico, sendo influenciadas, sobretudo, pelas distinções existentes entre os inventários fonético-fonológicos dessas duas línguas.

Por fim, podemos dizer que o tema deste artigo envolve questões de identidade linguística e cultural, pois o ato de nomear um estabelecimento comercial ou um produto com palavras estrangeiras é carregado de valor simbólico, pois, ao mesmo tempo em que 
muitos comerciantes acreditam que o estrangeirismo valoriza seu negócio, alguns consumidores também tendem a apreciar mais essas lojas.

\section{REFERÊNCIAS}

ASSIS, A. B. G. de. Adaptações fonológicas na pronúncia de estrangeirismos do inglês por falantes de Português Brasileiro. 2007. 266 f. Dissertação (Mestrado em Linguís tica e Língua Portuguesa) - Faculdade de Ciências e Letras, Universidade Estadual Paulista Júlio de Mesquita Filho, Araraquara.

BISOL, L. O ditongo na perspectiva da fonologia atual. D.E.L.T.A., São Paulo, v.5, n.2, 1989. p. 185-224.

CAGLIARI, L. C. Elementos de fonética do português brasileiro. São Paulo: Paulistana, 2007. 194 p.

Fonologia do Português - Análise pela Geometria de Traço e pela fonologia lexical (Parte II). Campinas: edição do autor, 1999. 157 p.

CÂMARA JR., J. M. Problemas de linguística descritiva. Petrópolis: Vozes. 2010[1969]. $71 \mathrm{p}$.

CARVALHO, N. Empréstimos linguísticos na língua portuguesa. São Paulo: Cortez, 2009. $95 \mathrm{p}$.

COLLISCHONN, G. A sîlaba em português. In: BISOL, L. (Org.). Introdução a estudos de fonologia do português brasileiro. 4. ed. Porto Alegre: EDIPURCS, 2005[1996]. p. 101-133.

CRYSTAL, D. English as a Global Language. Cambridge: Cambrige University Press, 2003. $212 \mathrm{p}$.

FIORIN, J. L. Considerações em torno do Projeto de Lei no 1676/99. In: FARACO, C. A. (Org.). Estrangeirismos: guerras em torno da língua. 3. ed. São Paulo: Parábola, 2004. p. 107-125.

FREITAS, M. A. de. Empréstimos, teoria auto-segmental e abertura vocálica. Cadernos de Estudos Linguísticos. Campinas: 1992. p. 71-81.

Os Empréstimos do Inglês no Português do Brasil. 1984. 201 f. Dissertação (Mestrado em Linguística) - Faculdade de Letras, Universidade Federal do Rio de Janeiro, Rio de Janeiro, 1984.

FREITAS, M. A. de; NEIVA, A. M. S. Estruturação silábica e processos fonológicos no inglês e no português: empréstimos e aquisição. Revista Virtual de Estudos da Linguagem (ReVEL). Ano 4, n.7, p. 1-27, ago. 2006. Disponível em: <http://paginas.terra.com.br/educacao/revel/>. Acesso em: 30 jan. 2010.

GARCEZ, P. M.; ZILLES, A. M. S. Estrangeirismos: desejos e ameaças. In: FARACO, C. A. (Org.) Estrangeirismos: guerras em torno da língua. 3. ed. São Paulo: Parábola, 2004. p. 15-36.

HOGG, R.; McCULLY, C. Metrical Phonology: a coursebook. Cambridge: Cambridge University Press, 1999[1987]. 279 p. 
LEE, S.-H. Epêntese no Português. In.: Estudos Linguísticos XXII-Anais dos Seminários do GEL. Ribeirão Preto: Instituição Moura Lacerda, 1993. v.II, p.847-854.

LOPEZ, B. The sound pattern of Brazilian Portuguese (Cariocan dialect). 1979. $304 \mathrm{f}$. Tese (doutorado, $\mathrm{PhD}$ ) - Los Angeles: University of California.

MACEDO, N. Z. Análise fonológica de nomes próprios de origem estrangeira e novas criações em Português Brasileiro. 2015. 171 f. Dissertação (Mestrado em Linguística e Língua Portuguesa) - Faculdade de Ciências e Letras, Universidade Estadual Paulista, Araraquara.

MASSINI-CAGLIARI, G. Changing Attitudes: Ways of Phonologically Adapting Proper Names in Archaic Brazilian and European Portuguese. In: KOLOKONTE, M.; JANKE, V. (Org.). Interfaces in Language 3. 1. ed. v. único. Newcastle upon Tyne: Cambridge Scholars, 2013. p. 159-178.

Loans and foreign first names as clues to Phonological Identity in Brazilian Portuguese. In: HORNSBY, D. (Org.). Interfaces in language 2. 1. ed. v. 1. Newcastle upon Tyne: Cambridge Scholars, 2011a. p. 53-67.

Adaptação fonológica de nomes próprios de origem estrangeira: comparação entre Português Arcaico e Português Brasileiro. Estudos Linguísticos, São Paulo, 40 (2), p. 795, mai.-ago. 2011 b.

Discutindo questões de identidade a partir da (não) adaptação fonológica de nomes próprios de origem estrangeira no Brasil. In: NEVES, M. H. de M. As interfaces da gramática. Araraquara: FCL-UNESP Laboratório Editorial; São Paulo: Cultura Acadêmica, 2010. (Série Trilhas Linguísticas 18). p. 73-90.

PAIVA, V. L. M. de O. e. A língua inglesa enquanto signo na cultura brasileira. 1991. 312 f. Tese (Doutorado em Linguística) - Faculdade de Letras, Universidade Federal do Rio de Janeiro, Rio de Janeiro.

PRADO, N. C. A influência da língua inglesa na formação de nomes comerciais: questões de identidade linguística e cultural. 2014. 343 f. Tese (Doutorado em Linguís tica e Língua Portuguesa) - Faculdade de Ciências e Letras, Universidade Estadual Paulista, Araraquara.

ROACH, P. English Phonetics and Phonology: a pratical course. Cambridge: Cambridge Universtiy Press. 1998. 262 p.

SOUZA, S. M. L. S. de. Antropônimos de origem inglesa: adaptações ortográficas e fonético-fonológicas realizadas por falantes do português brasileiro de São Luís-MA. 2011. 247 f. Tese (Doutorado em Linguística e Língua Portuguesa) - Faculdade de Ciências e Letras, Universidade Estadual Paulista, Araraquara.

WELLS, J. C. Longman pronunciation dictionary. $3^{\text {rd }}$ ed. Edinburg Gate: Pearson, 2008. $922 \mathrm{p}$.

ZUCARELLI, F. E. Ditongos e hiatos nas cantigas medievais galego-portuguesas. 2002. 155 f. Dissertação (Mestrado em Linguística e Língua Portuguesa) - Faculdade de Ciências e Letras, Universidade Estadual Paulista, Araraquara. 
Recebido em: 01/10/2015

Aprovado em: 31/01/2016 